\title{
BIM technology diffusion study in construction enterprises based on Bass model
}

\author{
Xiao Ling Tang ${ }^{1, a}$, Xiao Hai $\mathrm{Yi}^{2, b}$ \\ ${ }^{1}$ School of Xi'an University Of Architecture And Technology, Xi'an 710055, China; \\ ${ }^{2}$ School of Xi'an University Of Architecture And Technology, Xi'an 710055, China; \\ atangxiaoling@xauat.edu.cn, ${ }^{\mathrm{b}} 249685418 @ q q . c o m$
}

Keywords: BIM, technology diffusion,Bass model, Construction enterprises, Matlab;

\begin{abstract}
The emergence and development of BIM technology to improve the construction quality and construction efficiency, reduce the construction cost and contract dispute provides a technology platform. This article embarks from the technology diffusion of the Bass model, by 19 kinds of information technology innovation diffusion analogy of BIM technology diffusion coefficient of innovation $\mathrm{p}$ and coefficient of imitation $\mathrm{q}$. Through the Matlab software to draw the BIM technology diffusion trend curve of construction enterprises in our country, From the curve we can get, 2012 to 2022 BIM technology will be rapidly promoted and used in China's construction enterprises. In the future years, the construction enterprises should actively participate in the application of BIM technology,vying for the application of BIM technology leader,offers a good opportunity for the future development of enterprises with a higher platform.
\end{abstract}

\section{Introduction}

Building Information model is usually referred to as BIM, Now about BIM relatively complete definition is the U.S. national BIM standard definition: BIM is the digital expression of facility's physical and functional characteristics; BIM is a shared knowledge resource, is a sharing of information about the facilities and provide a reliable basis for the process of the facility from concept to dismantle the entire life cycle of all decision-making; In different stages of the project, different stakeholders by BIM insert, extract, update and modify the information to support and reflect the respective responsibilities of work.

\section{The application of BIM technology}

The emergence of BIM technology is another technical innovation after the CAD technology in the field of construction. If the BIM technology and has now been used widely in CAD technology comparison we will find, CAD technology is actually a computer software replaces the traditional hand-drawing mode, and BIM is carried through the whole life cycle of the project, is a physical and functional characteristics of digital expression of the project. BIM project work flow chart shown in Figure 1. The application of BIM in construction enterprises is mainly manifested in the bidding, construction and completion settlement period. In the bidding and tendering stage application of BIM can improve competitiveness, help construction companies get a better settlement profits,enhance successful rate of the bid. Application of BIM in construction stage is able to reduce the potential risk factors that may affect days for construction, and make the technical staff have a better understanding to these design drawings and Improve project technical staff familiarity with the project. Construction project completion settlement is the last link in the construction process, is the ultimate sign of construction project construction cost, also is the last part of the project cost control, directly related to the vital interests of the project owner and the contractor, at this stage to establish on the basis of the BIM model of completion settlement audit process, can improve the settlement on the basis of the review of effectiveness, implementation completion and settlement of careful accounting, fully efficient and accurate settlement results. 


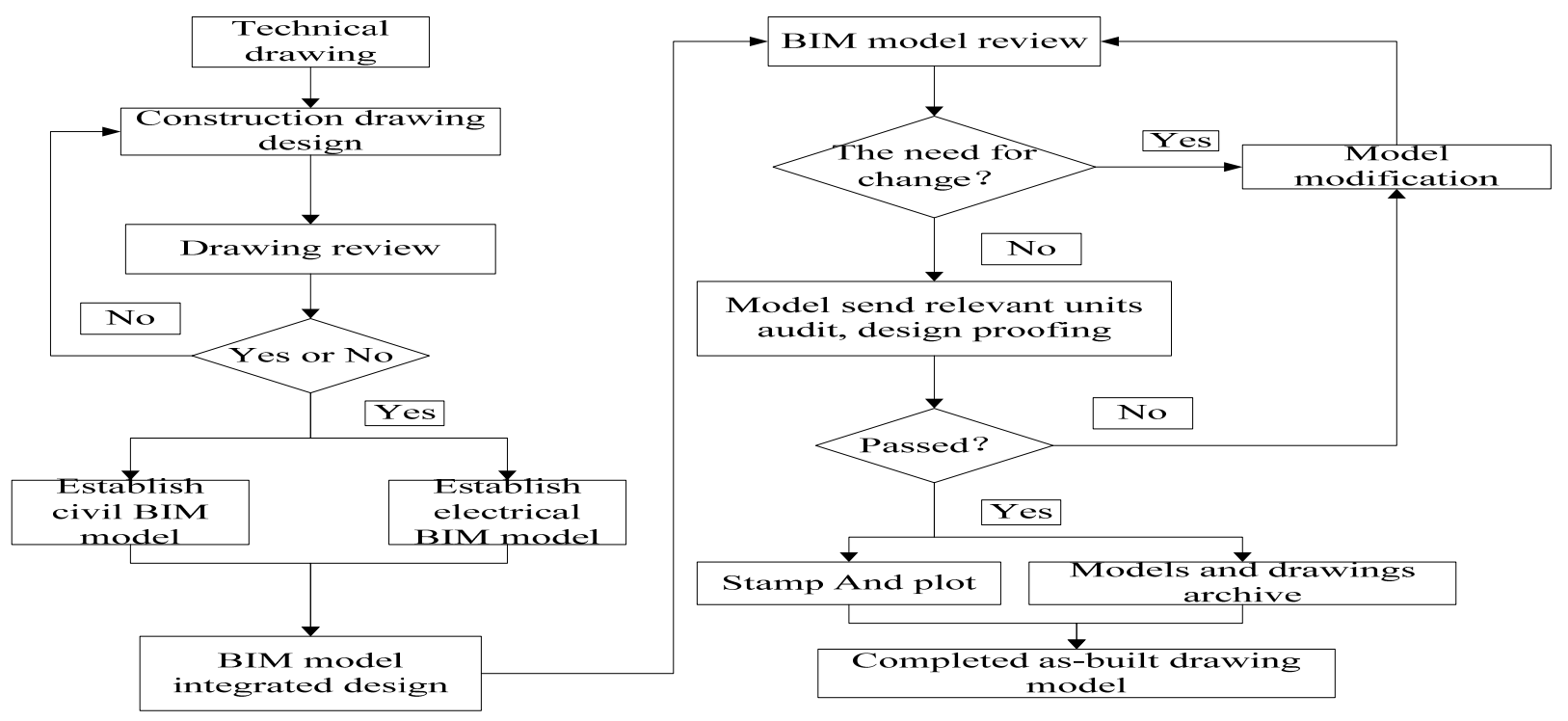

Figure 1 BIM project work flow chart

\section{BIM technology diffusion and Bass model}

BIM technology diffusion.Technology diffusion is a subsequent process of technological innovation,technological innovation through certain channels to spread among potential users, that is a complete system of technology diffusion by subject, diffusion channels, technology adopters all three are indispensable,it is an organic whole interconnected. For BIM technology diffusion, generally speaking, the spread of the subject is to provide BIM technology companies, but such a division is comprehensive enough, it can also be a scientific research institution, the spread of the relevant government departments and relevant intermediary institutions, etc. For BIM technology provided by the enterprise, its spread is to occupy the market share and achieve the purpose of enterprises maximize profits. For scientific research institutions, its spread to recycle into capital and achieve a certain profit of technology innovation. Diffusion channels refers to the ways to make technology through certain adopters to obtain information about the technology, and decide whether to adopt the technology can bring some to adopters himself or enterprise profit or increase in labor productivity, so as to realize the application of BIM technology,Mainly include two types: the mass media and interpersonal communication.

Bass model.For technology innovation diffusion, application and new products sales forecasts, there are mainly three kinds of commonly used model, namely the Bass model, the Gompertz model and Logistic model, and Bass model is the most widely used. when a new product or new technology to market, the rate of diffusion is only affected by the mass media and interpersonal communication, in which the mass media mainly includes advertising, sales promotion and other external influence. Interpersonal communication refers to adopters after using the product or technology to potential adopters of internal, such as propaganda, mainly about ease of use, durability and reliability of the product performance, etc. Accordingly in the Bass model, the adopters of the new technology can be divided into two groups, one group only because of the influence of mass media, the other is influenced by interpersonal communication, only we put before a group called the innovator, after a group called the imitator. The basic form of Bass model as follows:

$$
\frac{\mathrm{dN}(\mathrm{t})}{\mathrm{dt}}=\left[\mathrm{p}+\frac{\mathrm{q}}{\mathrm{M}} \mathrm{N}(\mathrm{t})\right] \times[\mathrm{M}-\mathrm{N}(\mathrm{t})]
$$

$p$ means innovation factor, $q$ means imitation coefficient, $N(t) t$ time accumulative total number of adopters, $\mathrm{M}$ for technology adoption is one of the biggest market potential. On type (1) deformation and integral can be cumulative time function of adopters $N(t)$ :

$$
N(t)=M \times \frac{1-e^{-(p+q) t}}{1+\frac{q}{p} e^{-(p+q) t}}
$$


Bass model parameter estimation. $M, p, q$, if we know the value of the three coefficients, we can get $\mathrm{t}$ time the cumulative number of adopters. General with experts predict method to obtain the biggest potential value of $\mathrm{M}$. For estimating parameters of $\mathrm{p}, \mathrm{q}$, can be divided into two situations: one kind is plenty of data of parameter estimation, the other is a parameter estimation of data is not enough. When lack of sufficient data to predict the technology diffusion, the commonly used methods of parameter estimation has analogy method and judging method. The spread of the so-called analogy method is through a similar technique to obtain the technology of $p, q$, and then through the Bass model determine the proliferation of this technology. Judgment method is to point to by experts on the market, most potential $\mathrm{M}$, sales of extreme value and the time of judgment, and then the parameters estimation of $\mathrm{p}$ and $\mathrm{q}$.

\section{The diffusion trend of BIM technology in the construction enterprises}

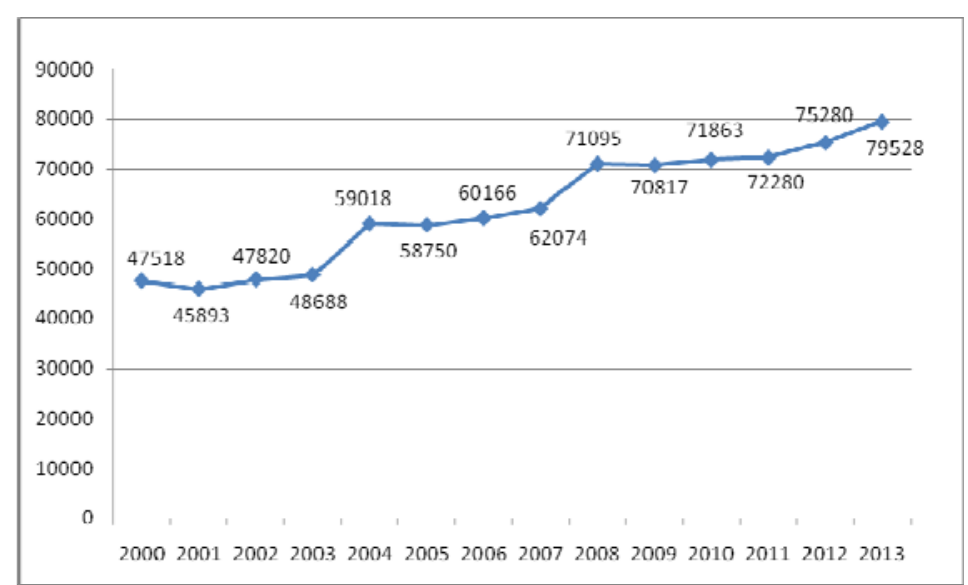

Figure 2 the number of construction enterprises in our country in 2000 to 2013 years

Largest market potential prediction of $\mathbf{M}$. With the rapid development of construction industry in our country in recent years, with the corresponding construction enterprises have experienced from less to more change process. We can see from figure 2 , the number of construction enterprises in our country increased from 2000 in 47578 to 2013 in 79528, the growth rate reached $67.2 \%$. One of the fastest growing year, respectively, 2004, 2008, 2012, 2013, these four years, the number increased compared to last year's number of $10330,9021,3000,9021$, accounting for $83.3 \%$ of the total growth rate, and over the years our country real estate market reached a climax. Has experienced rapid growth year after 2001, 2005, 2009, three years, the number a slight reduction in the number of relative to the previous year, reduce the amount of 1625, 268, 268 respectively. Other years although the number has increased, but the increase in the number is not much, basic stable.

Through the above analysis we can conclude that in the future for a period of time in our country construction enterprise will further increase, but with the development of our country's real estate market gradually return to rational, the increase of the number of construction enterprises will not appear again by leaps and bounds, the increase would be a stable process. Through the expert investigation and analysis, in the next ten years, our country's construction enterprises will reach between 90000 and 95000, and will use BIM technology construction enterprises will account for about $80 \%$ of the number of the whole industry enterprises. So we in estimating the largest potential market value can be value to 75000 .

Innovation and imitation coefficient estimate. Since 2002 the introduction of BIM technology in our country, although experienced a decade of development, but in terms of the depth and breadth of application, the application and research of BIM technology in our country is still in its infancy, and its application in the design of the unit, and its research mainly concentrated in universities or institutes, but with the passage of time will gradually spread to all areas of the construction industry. With the 2011-2015 construction industry information development outline, for the application of BIM technology started on the right track in our country, has entered the phase of rapid development. 
Because of BIM technology in our country construction enterprise development process is slower, so there is not enough historical data can be for our reference, in the estimation of the coefficient of innovation and imitation, When insufficient data are often used with analogy method and judging method. J. c. Teng Bass used model for 5 kinds of similar information technology innovation diffusion is studied, using least squares estimation of the parameters $\mathrm{p}, \mathrm{q}$.

Table 1 Bass model parameter estimates

\begin{tabular}{|l|c|c|c|}
\hline Information technology innovation & $\mathrm{p}$ & $\mathrm{q}$ & inflexion time \\
\hline 1、4GL & 0.0037 & 0.3089 & 1987 \\
\hline 2、CAD/CAM & 0.0048 & 0.3186 & 1987 \\
\hline 3、EDI & 0.0002 & 0.2980 & 1992 \\
\hline 4、E-mail & 0.0008 & 0.3303 & 1989 \\
\hline 5、 Relational data & 0.0006 & 0.3074 & 1991 \\
\hline
\end{tabular}

From the BIM technology in some developed countries in the development process, its in the early development is slow, after the relevant government departments to formulate relevant policy guidance significantly speed up the development speed. BIM technology as the CAD technology in the construction industry after another technology revolution, both in the whole process has a great deal of similarity. On BIM technology diffusion coefficient in the estimation of $p$, q, we take the five information technology innovation diffusion coefficient of arithmetic mean, so when the Bass model for BIM technology in the construction enterprise to study the diffusion trend, innovation coefficient $\mathrm{p}$ value is 0.00202 , the model coefficient $\mathrm{q}$ value of 0.31256 . Through the Matlab software, we can draw the BIM technology diffusion trend diagram of construction enterprises in our country.

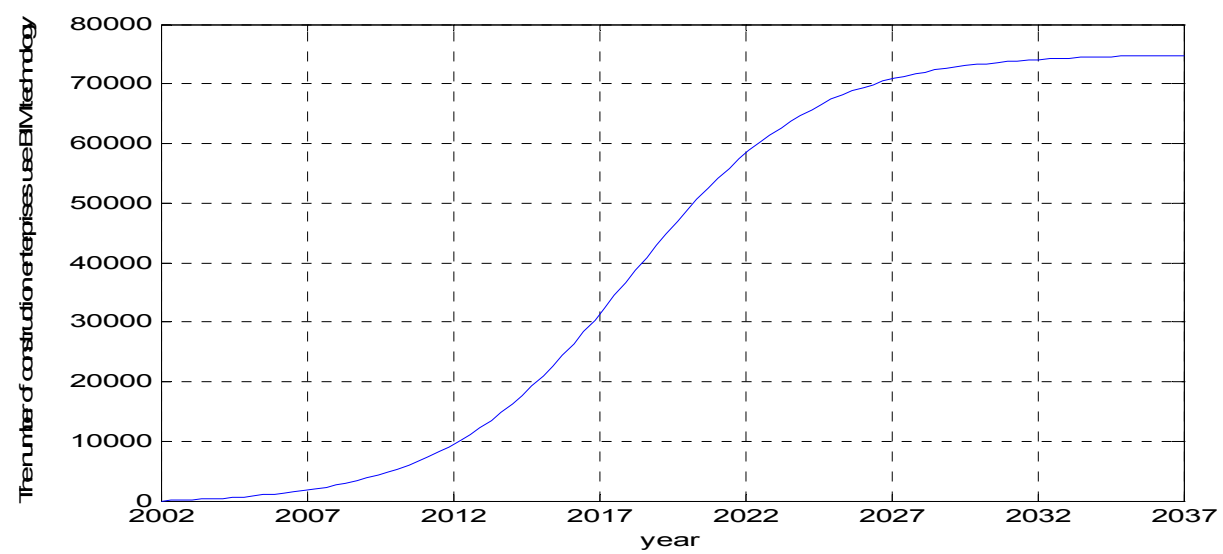

Figure 3 BIM technology diffusion trend of construction enterprises in our country

\section{Summary}

From 2012 to 2025 BIM technology will be rapidly promoted and used in China's construction enterprises. In the future years, the construction enterprises should actively participate in the application of BIM technology,vying for the application of BIM technology leader,offers a good opportunity for the future development of enterprises with a higher platform.

\section{Acknowledgments}

This study was supported by the "BIM technology diffusion mechanism research"(13JZ027), Philosophy Social Science Research base in ShanXi province department of education project.

\section{References}

[1] National Institute of Building Sciences, United States National Building Information Modeling Standard, Version1-Part 1[R]. 
[2] Chinese statistics yearbook 2014. [J]. National Bureau of Statistics .

[3] J. C. Teng, V. Grover, Wolfgang GÜttler, Information technology innovation: General diffusion patterns and its relationships to innovation characteristics, IEEE Transactions on engineering Management [J]. Vol. 49, No. 1, February 2002, 13-27. 